\section{(2) OPEN ACCESS}

\title{
'Master My Demons': art therapy montage paintings by active-duty military service members with traumatic brain injury and post-traumatic stress
}

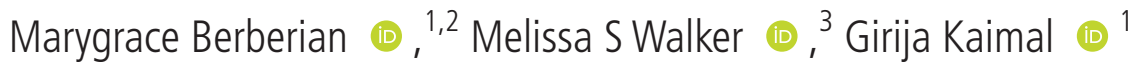

\begin{abstract}
${ }^{1}$ Creative Arts Therapies, Drexel University College of Nursing and Health Professions, Philadelphia, Pennsylvania, USA ${ }^{2}$ Art \& Arts Professions, New York University, Steinhardt, New York, New York, USA ${ }^{3}$ National Intrepid Center of Excellence (NICOE), Walter Reed National Military Medical Center, Bethesda, Maryland, USA
\end{abstract}

\section{Correspondence to}

Professor Girija Kaimal, Drexel University College of Nursing and Health Professions, Philadelphia, PA 19034, USA; gk27@drexel.edu

Accepted 21 June 2018 Published Online First 4 August 2018

\section{Check for updates}

(c) Author(s) (or their employer(s)) 2019. Re-use permitted under CC BY-NC. No commercial re-use. See rights and permissions. Published by BMJ.

To cite: Berberian $\mathrm{M}_{\text {, }}$ Walker MS, Kaimal G. Med Humanit

2019:45:353-360.

\section{ABSTRACT}

This study involved a thematic analysis of montage paintings and of related clinical records of 240 activeduty military service members collected during their art therapy treatment for traumatic brain injury and underlying psychological health concerns, including post-traumatic stress, at the National Intrepid Center of Excellence, Walter Reed National Military Medical Center, Bethesda, Maryland, USA. Congruent with other research findings, the qualitative analyses of this study suggest that the group art therapy experiences fostered improvement in interpersonal relatedness, hopefulness and gratification for the service members in treatment, aiding in externalisation, progressive exposure and construction of a trauma narrative imperative for recovery. The mixed media nature of the montage painting supported the expression of a range of postcombat symptoms. Results from this study highlighted the complexity of military culture, necessitating a broader scope of analyses for how art therapy helps service members express and communicate their challenges to care providers, peers and family as well as regulate emotion in the short and long term.

\section{INTRODUCTION}

More than 2.6 million US military service members have been deployed since 2001 in our post 9/11 world. ${ }^{1}$ Unlike other military service periods in history, recent conflicts have led the all-volunteer military to participate in multiple deployments that are often long and that severely restrict the time at home between deployments, thereby adding significant stress to their situations. ${ }^{2}{ }^{3}$ Additionally, the newly adaptive body armour developed to protect them against explosive devices in combat has enabled service members to endure greater risk and thereby increased the number of service members returning home with 'polytrauma. ${ }^{4}$ Polytrauma has been defined as the impact of multiple injuries that may be life-threatening and result in impairments in cognitive, psychological, psychosocial and physical functioning. ${ }^{4-6}$ Consequently, 375230 military service members have been diagnosed as having suffered a traumatic brain injury (TBI) since 2000 . Further, in a survey administered by the Veterans Administration from 2006 to 2010, an estimated 480748 service members were found to be struggling with post-traumatic stress disorder (PTSD). ${ }^{1}$

The number of veterans who received mental healthcare increased from $4 \%$ in 2006 to $12 \%$ in 2010. ${ }^{1}$ However, many veterans suffering with mental health issues do not seek help and others diminish the severity of their issues. ${ }^{8}$ Verbally expressing symptoms is a challenging limitation for those who have been traumatised. ${ }^{9} 10$ As an alternative intervention, the visual expression afforded by art therapy is increasingly gaining acceptance as a treatment for service members with PTSD and TBI. ${ }^{11-14}$

\section{ART THERAPY FOR MILITARY SERVICE MEMBERS WITH TBI AND PTSD}

Art therapy relies on art making and creative processes within a psychotherapeutic relationship to improve or restore functioning and/or a sense of well-being. ${ }^{15}$ The need for self-expression by service members has been identified as important for recovery and reintegration into civilian and family life. ${ }^{16}{ }^{17}$ Art therapy addresses the effects of deployment and combat as well as the emotional impact associated with TBI, PTSD and/or comorbid psychological disorders sustained as a result of being a witness, victim or agent of combat or related events. 113141718

Within integrative military medical care settings, art therapy has gained recognition as a form of complementary care. ${ }^{11} 1819$ Art therapy provides visual expression for the unspeakable symptoms caused by combat engagement. ${ }^{11} 1417$ As an overwhelming psychic experience, trauma can often be somatically stored. ${ }^{10} 20$ Symptoms such as expressive and emotional numbing, along with other ailments, are ameliorated through the art therapy processes, which form images for the internal wounds of combat. ${ }^{14} 1721$ For trauma survivors, the retelling and reformulation of the terrorising memories through pictorial, non-verbal iteration can generally be less threatening than verbal disclosure because much is mitigated through the visual symbolism. ${ }^{22-24}$

Current research has identified therapeutic elements implicit in art therapy that could address symptoms of combat-related post-traumatic stress (PTS): (1) progressive exposure, (2) externalisation for processing, (3) reactivation of pleasure, (4) promotion of self-efficacy through mastery and (5) formulation of a reconsolidated narrative. ${ }^{12} 2225-28$ Gantt and Tinnin ${ }^{26}$ recommended that art therapists develop approaches for trauma recovery that integrate fragmented traumatic experiences into a coherent narrative and reduce dissociation by externalising the dialogue between verbal and non-verbal states. The goal is to remember rather 
than relive the experiences of terror. ${ }^{29}$ The emotional burden of the trauma often destabilises the survivor, creating hopelessness and helplessness, leading to what van der Kolk terms 'speechless terror'. ${ }^{1030}$ For trauma survivors, there is often a suppression of emotional expression and an inability to master cognitive awareness and engage in verbal processing. ${ }^{31}$

The internal anguish that underlies memory and emotion may be uncovered and managed through art making, which provides opportunities for mastery and control not otherwise available in more traditional modes of therapeutic intervention. ${ }^{17}$ Emotional distance can be gained when the art processes summon the assertion of power and mastery by externalising those fragmented somatic and conscious memories. ${ }^{32}$ Because art making is an iterative process to reformulate new narratives through the doing/ undoing process, newer integrations of memories are rehearsed at one's own pace and break rigid thought patterns. ${ }^{28}$ This process is especially helpful because TBI and PTSD symptoms can impair cognitive processing for injured service members. ${ }^{334}$

Because art making is often a gratifying, emotionally rewarding experience, survivors will often experience a reactivation of pleasure in art therapy. ${ }^{22}$ Enhanced self-efficacy has long been linked to motivation-seeking behaviours. ${ }^{35}$ Collage is one method of art making that has been found to reduce stress and decreases anxiety. ${ }^{36}$ The juxtaposition of disconnected visual forms brings new meanings and awareness in this new configuration that joins text to image. ${ }^{3738}$ This multilayered process, when combined with painting, was described as 'montage painting' close to 50 years ago by Andre Verlon ${ }^{39}$ during another period of international military conflict. Verlon advocated for this innovative approach to art making as a social response of the time. He wrote:

My intention is not only to bring out the quintessence of the polarity of the problems of modern reality: construction-destruction, securityfear, civilization-barbarity, man-machine, movement-blockage, etc.; but also to probe the fundamental interplay beneath the conflicting forces of technology, profit, fear, violence and man's hope for a better world. $\left({ }^{39}\right.$, p. 383)

Clinical observations indicate that group art therapy is highly effective with service members because it allows the strengths of the community-based military culture to benefit the individual participant. ${ }^{40}$ It is the strength of the unit's cohesion that shields the adversity of combat, the development of PTSD and possibly suicidality. ${ }^{41}$ Herman notes,

Those who have survived learn that their sense of self, of worth, of humanity, depends upon a feeling of connection to others. The solidarity of a group provides the strongest protection against terror and despair, and the strongest antidote to the traumatic experience. Trauma isolates; the group re-creates a sense of belonging. Trauma shames and stigmatizes; the group bears witness and affirms. Trauma degrades the victim; the group exalts her. Trauma dehumanizes the victim, the group restores her humanity. ${ }^{42}$, p. 214$)$

At the National Intrepid Center of Excellence (NICoE) Intensive Outpatient Program at the Walter Reed National Military Medical Center in Bethesda, Maryland, USA, art therapy has been effective in the rehabilitation of injured service members coping with comorbid TBI and psychological health conditions. ${ }^{13} 144344$

\section{Setting}

Art therapy in the integrative setting of NICoE effectively ameliorated symptoms for injured service members managing
TBI and co-occurring mood disorders since 2010. ${ }^{13} 4344$ This intensive outpatient programme is an integrative care model with an outlined treatment protocol over the course of 4 weeks. In art therapy, service members are assessed in both group and individual sessions. In the first week of treatment, service members create three-dimensional masks in group art therapy sessions. Mask making in art therapy has become an integral part of the treatment at NICoE. Even before the first art therapy session is held, the visible displays of the masks proudly exhibited in public areas coupled with the extensive media coverage of these works have implicitly built trust in the art-making process. The masks aid the processing of traumatic memories related to TBI and combat through a more symbolic externalised representation. ${ }^{13} 144344 \mathrm{In}^{45}$ the group context, the masks help to organise overwhelming responses to combat injuries, channelling verbalisations that had been internally silenced. Service members often continue working on their masks while they receive other integrative services such as music therapy, animal-assisted therapy, medical and nursing care, physical therapy, family therapy and individual counselling.

In week 4 , the final week of treatment, service members are prompted to create montage paintings. This directive, designed by Walker, merges past and present experiences as a multilayered, multimedia art form. ${ }^{44} 45$ Presented with an $8^{\prime} \times 10^{\prime}$ canvas, service members are invited as follows:

\section{Some people choose to just paint and then they might use collage to embellish certain things, or they may collage and then paint to embellish certain things or they may go back and forth. You can doc- ument or process something from the past, or focus on where you are currently, or on hopes, goals, or concerns for the future. There are two different ways to approach this, you can either have an idea in your mind of exactly what you want it to look like and you can spend the session actualizing that image, or you can have no idea of what you want it to look like, no idea what you want it to be about and just spend some time going through magazines, cutting out any words or images that resonate with you for whatever reason. It can be a really insightful process to then organize what you've collected on to your canvas. $\left({ }^{43}\right.$, p. 3$)$}

Service members are able to choose from a generous array of art materials including paints, printed images and clay.

Analyses of the montage paintings created by service members are described in this paper. The study design was a qualitative thematic analysis ${ }^{46}$ of images created in the montage paintings and the descriptions provided by participants.

\section{METHODS \\ Study participants}

Demographic data were available for 208 out of 240 study participants. Service members from all branches of the Armed Services were included in this study. These participants were managing comorbid symptoms of combat-related TBI and psychological health conditions. Participants $(n=208)$ ranged in age from 21 to 59 years $($ mean $=35.75, S D=7.43)$ and predominantly identified as men $(97.1 \%, \mathrm{n}=202)$. The racial and ethnic distribution was as follows: White, $88.5 \%$; Hispanic, 5.8\%; Black, 2.9\% and Asian/Pacific Islander, 2.9\%. Although service members were affiliated with all five branches of military service, the Navy was the most represented $(44.7 \%, \mathrm{n}=93)$. The majority of service members were enlisted (83.2\%). The remaining participants were officers, many of whom were special operations. The time of service ranged from 1.5 to 33 years $($ mean $=14.68, \mathrm{SD}=7.11)$. 


\section{Data sources}

Data sources for the study included (1) photographs of montage painting artwork created by service members and (2) documented clinical notes. Data collected from the mask analyses were also used for comparison. ${ }^{14}$ Participants' verbal descriptions of the symbolism embedded in the artwork and their resulting experiences were captured in clinical notes. These notes, about 50-100 words, and photographs of the artwork were uploaded as part of electronic medical record documentation into a common military patient charting and medical information database. Additional demographic information was also available on participants' age, gender and military rank. More than 800 paintings have been made over the past 6 years. Data including consent for analysis, photographs of the montage paintings and concurrent notes were available for 240 participants. Demographic information was available for 208 participants.

\section{Data analysis}

An iterative process informed by thematic analysis was used to analyse the data. ${ }^{46} 47$ Photographs of the montage paintings were first extracted from the data files and reviewed collectively to identify visual themes for open coding. These themes were compared with the first data set collected from the masks. Pictorial and symbolic representations, as well as visual elements such as colour, media and composition, were noted. The list of codes was reviewed for consensus and cross-referenced with the study sample for axial coding. An exhaustive total of 174 codes were ultimately generated to capture the frequencies of observations such as verbal descriptions of memories of deployment or the artistic choice to use text in the montage paintings. Clinical notes from the group art therapy sessions and the culminating artwork were coded qualitatively through a Web application for mixed methods research applicable for the social sciences. ${ }^{48}$ One coder reviewed the sample. Another coder reviewed the data set, and each coding discrepancy was discussed to achieve consensus. Verbal, behavioural and visual elements of the clinical encounter were comprehensively examined. These findings were then compared with the results analysed for the data set of the masks. Because the same codes were used, comparisons could be drawn from the two time points: week 1 (masks) and week 4 (montage paintings). The changes in frequencies noted between these two data sets are substantial and identify areas for future examination.

\section{RESULTS}

The data analysed included clinical documentation and artwork of injured service members $(n=240)$ who participated in group art therapy. Code occurrences were computed for frequency.
Table 1 shows the codes yielding the highest frequencies in the data analyses. ${ }^{1}$

\section{Art-making experience: Pleasure, socialisation and openness elicited}

Data collected from the montage paintings indicated that group art therapy was beneficial. Participants specifically commented about their enjoyment $(41.3 \%, \mathrm{n}=99)$, were able to share artwork with peers and clinicians $(30.4 \%, n=73)$ and voiced concerns and feelings about experiences related to their injuries $(35.4 \%, \mathrm{n}=85)$.

\section{Artwork: Use of text}

Almost half of the works (43.8\%) used preprinted or originally formed text in the compositions of the montage paintings. These words were mostly cut out of magazines; a few were written in with paint. Text included phrases or words exemplifying the service members' thoughts including famous quotes or fragments from songs and poems. This reliance on text suggests a greater need for mastery of the expressed content. Whereas some theorists see the use of words in expression as a form of intellectualisation, it is also regarded as an adaptive defence to manage the intensity of what is being processed. ${ }^{49} 50$ The transition from non-verbal to verbal processing through artistic processes, a notable observation from other research, is also evident in this study. ${ }^{11}$ Additionally, the use of words relates to cognitive rather than visceral reactions, which allows for emotional distancing and mastery. The use of text in the montage paintings is exemplified in figure $1 \mathrm{~A}, \mathrm{~B}$. In figure $1 \mathrm{~A}$, preprinted text is adhered to a painted background. Selected text includes 'BOOM', 'Finding My Place', 'The Eyes Say It All', 'Return to Reality' and 'What about the survivors?' Figure 1B depicts the painted words 'Putting pen to paper to write something profound is simpler than putting bullets to flesh'. The inclusion of either preprinted text or text inscribed by hand was coded independently. Although the processes and resulting montage paintings vary, each expresses personal postcombat reflections.

\section{Artwork: Nature as metaphor}

The use of metaphor is widely used in creative arts therapies as a change agent to challenge former thinking and birth new opportunities. ${ }^{51}$ Nature was the most frequent metaphor depicted in the montage paintings $(35 \%, \mathrm{n}=84)$. Service members seemingly related to nature as a safe realm for expressing conflicted material. Nature, often symbolic of dynamism, served to showcase the themes of aggressor/victim, fragility/grandeur, unpredictability and stability. Attempting to mitigate these dualities, service members examined their own internal conflicts through the nature-inspired art they

Table 1 Notable occurrences in montage data set thematic analyses

\begin{tabular}{|c|c|c|c|c|c|}
\hline & \multirow[b]{2}{*}{ Code } & \multicolumn{2}{|l|}{ Masks } & \multicolumn{2}{|l|}{ Montage } \\
\hline & & $\begin{array}{l}\text { Number of } \\
\text { occurrences }\end{array}$ & $\begin{array}{l}\text { Percentage of } \\
\text { total data set }\end{array}$ & $\begin{array}{l}\text { Number of } \\
\text { occurrences }\end{array}$ & $\begin{array}{l}\text { Percentage of } \\
\text { total data set }\end{array}$ \\
\hline \multirow[t]{3}{*}{ Art-making experience } & Enjoyable experience/Surprisingly enjoyable & 124 & $30.8 \%$ & 99 & $41.3 \%$ \\
\hline & Sharing artwork with clinicians/peers & 33 & $8.2 \%$ & 73 & $30.4 \%$ \\
\hline & Engaged socially/sharing concerns & 38 & $9.5 \%$ & 85 & $35.4 \%$ \\
\hline \multirow[t]{5}{*}{ Themes represented in the artwork } & Words/text & 58 & $14.4 \%$ & 105 & $43.8 \%$ \\
\hline & Expression of nature metaphors & 33 & $8.2 \%$ & 84 & $35.0 \%$ \\
\hline & Artwork as a life story & 48 & $11.9 \%$ & 69 & $28.8 \%$ \\
\hline & Memories of deployment & 33 & $8.2 \%$ & 52 & $21.7 \%$ \\
\hline & References to serenity/interests/strengths/hobbies/nature & 12 & $3 \%$ & 42 & $17.5 \%$ \\
\hline
\end{tabular}




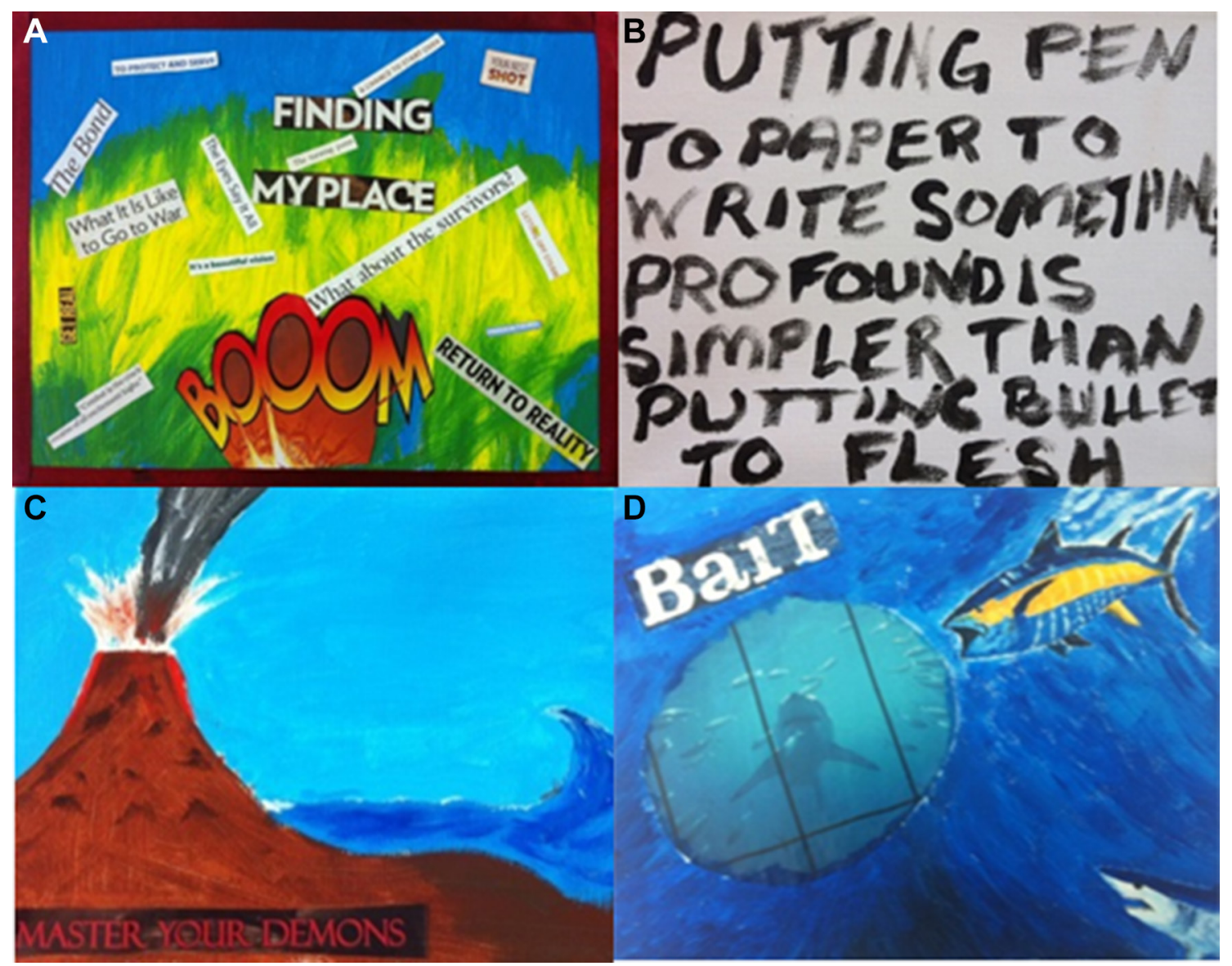

created. Internal struggles were projected onto the more universal, external environment. figure 1C,D reflects the montage paintings thematically coded for use of nature as a metaphor. In figure $1 \mathrm{C}$, an isolated volcano spews matter off the boundary of the canvas while preprinted text, 'Master Your Demons' is anchored at the bottom. In figure $1 \mathrm{D}$, an open-mouthed shark lurks in the water with other fish. The inclusion of the word 'Bait' speaks to the vulnerability of this predatory encounter.

\section{Artwork: Life story}

Early attempts to integrate the combat trauma into a more holistic biographical narrative in recovery are evident in figure 2A,B. The externalisation of autobiographical details aids memory processing by formulating a reconsolidation of memories through a newly constructed narrative. ${ }^{12} 2228$ The composition is visually divided in figure $2 \mathrm{~A}$ because there is a clear delineation between combat and postcombat life. A flaming 'TBI' lurks in the distance amid the headstones of those who were killed in combat. The short, coloured lines show the meticulous efforts taken to include the details in a methodical manner. With the American flag centred on the page, each side of the barracks suggests divergent scenes. In figure $2 \mathrm{~B}$, the montage painting reflects the service member seeking salvation, as he inscribed 'God Deliver Me From Evil'. He regretted the burden his military experiences had perceivably imposed on his family. The execution of the paint material appears less controlled in this image and the brown colour both camouflages and conceals the words. Red colour is used for the word 'Evil' which is also splattered cross the stick figures above the word 'Family.'

\section{Memories of deployment}

In comparison to the mask data, there was a $13.5 \%$ increase in service members' expression of deployment memories, rising from $8.2 \%$ in week $1 \%$ to $21.7 \%$ in week 4 . After 4 weeks of treatment, safety established through trust in the treatment seemingly encouraged more difficult memories to be more readily activated. Progressive exposure to combat memories aids trauma recovery and aligns with previously accounted research findings. ${ }^{22} 2632$ Figure $2 \mathrm{C}$ is a montage painting coded for memories of deployment. Covered first in camouflaged fabric, the montage painting included images of badges, weapons and service members in combat. Images of the service member's own military division are also included. His verbalisations during the group process described his yearning to return to combat. The montage serves as a non-linear way to capture the combat experiences concretely for integration into the personal narrative. ${ }^{43}$ Service members were able to 'remember' without 'reliving' the experience. ${ }^{29}$

\section{Artwork: References to serenity/interests}

Future goals were also described in the montage paintings. Service members relied on self-efficacy to outline personal goals post discharge. These images were largely hopeful and relate to the reactivation of positive emotion noted in existing research. ${ }^{112228}$ Figure 3A,B shows examples of montage paintings coded for references to serenity and interests. Figure $3 \mathrm{~A}$ reflects a barren mountain of solitude described as 'My Happy Place' from individually cut letters. Figure 3B depicts a human form in water. The service member explained the yellow and red 


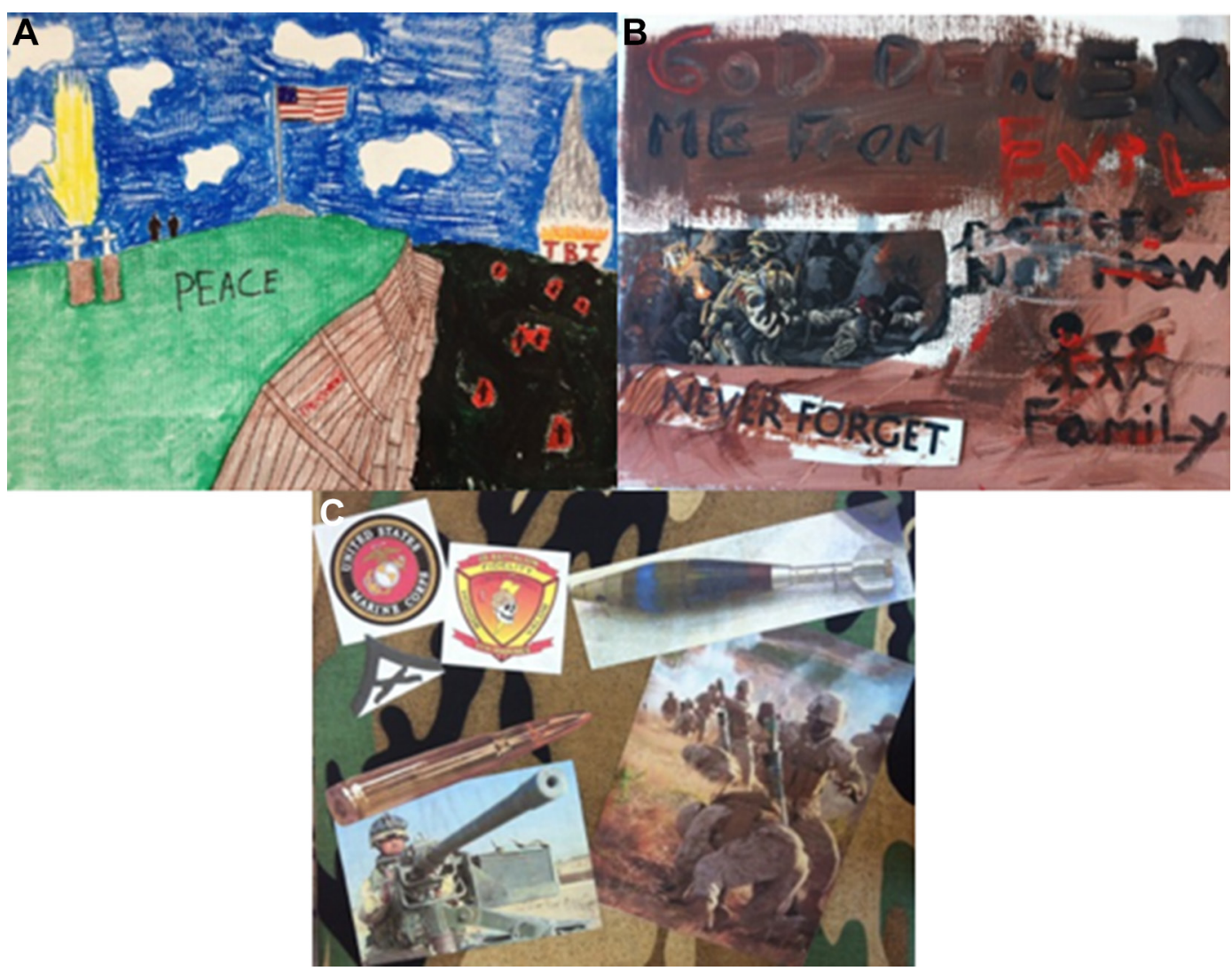

Figure 2 (A) Artwork exemplifies the service member's life story. The service member described that he wished to depict 'being in the trenches' (describing his deployment and injury), then the challenge of climbing out (reflecting his treatment at the National Intrepid Center of Excellence) to a brighter, better place. The service member reflected that one day life will end; he depicted this with a bright light and two shadows overlooking the fallen. (B) While struggling with head pain, the service member shared this work, explaining it represents how he has 'tainted' his family due to everything he has been through in the military. He shared his hopes, 'God deliver me from evil'. (C) The service member covered his canvas board in camouflage printed cloth. He printed and glued pictures related to his military career while sharing his desires to return to combat. He listened to his peers who suggested he has accomplished much in his life and will have the opportunity to accomplish more outside of the military.

paint strokes to be 'thoughts seeping in' from floating in warm water. While both images were described as serene associations, each holds a sense of isolation.

Hopefulness was also improved (11.1\%) over the course of 4 weeks in the data samples. Figure 3C,D is representative of montage paintings coded for hopefulness. Clinical notes describe, 'Pt stated the footprints represent where it all started, as well as the next steps he will need to take in his life (retirement)'. The footprints relate to the yellow painted footprints recruits stand on their first entry, symbolic of the structure established to stand in formation and recount all those who have served in the past. The drill instructor ritualistically recites, 'you have just taken the first step toward becoming a member of the world's finest fighting force, the United States Marine Corps'. This service member opted to include photographs with quotes in the back of his canvas frame to aid him in his transition to civilian life. The two quotes read, 'A journey of a thousand miles begins with a single step' and 'When I let go of what I am, I become what I might be'.

Figure $3 \mathrm{E}$ is also a montage painting coded for increased hopefulness. The service member used cork to cover the surface. Tasks are outlined on adhesive notes under the title 'Things To Do'. Selected notes read: 'Find God or religion or at least give it a try?', 'Talk the wife into not leaving', 'Be more friendly to people', 'Stop swearing at the kids, at the dog, at the neighbor, at myself', 'mow the lawn', 'drink less' and 'Go to the dinner party and act like you are having fun'. Evidence of self-efficacy as described in other research can be seen in this task-oriented, organised montage painting that outlined both short term and long-term personal goals. ${ }^{22} 2527$

\section{Other notable changes}

The montage painting data set from week 4 was compared with that from the masks created during week 1 . Other notable differential changes between the masks and montage paintings are as follows: (1) increased self-awareness and socialisation (26.9\%), (2) increased patriotism (11.8\%), (3) increased pleasure from art making $(10.5 \%),(4)$ greater awareness of psychological distress $(5.3 \%)$ and (5) decreased reporting of depression and anxiety (4.3\%).

Figure 4A,B shows montage paintings coded for increased selfawareness. In figure $4 \mathrm{~A}$, a service member depicts his experience of PTSD as being non-human, pictorially illustrated as 'The Hulk' character. The preprinted words 'getting to know you' align with his verbal statements about trying to connect with the 'who' he is inside. The centralised text, 'Can you honor the power inside you' parallels the intentional efforts to fit the images together tightly in a puzzle-like composition so each is visually held by the other. Figure 4B incorporates a three-dimensional switch in its visually divided composition. The service member depicted his two (although unequally divided) sides: a fiery, aggressive facet labelled as a 'monster' and a more compliant side, embellished with packaged sweetener flanked by 


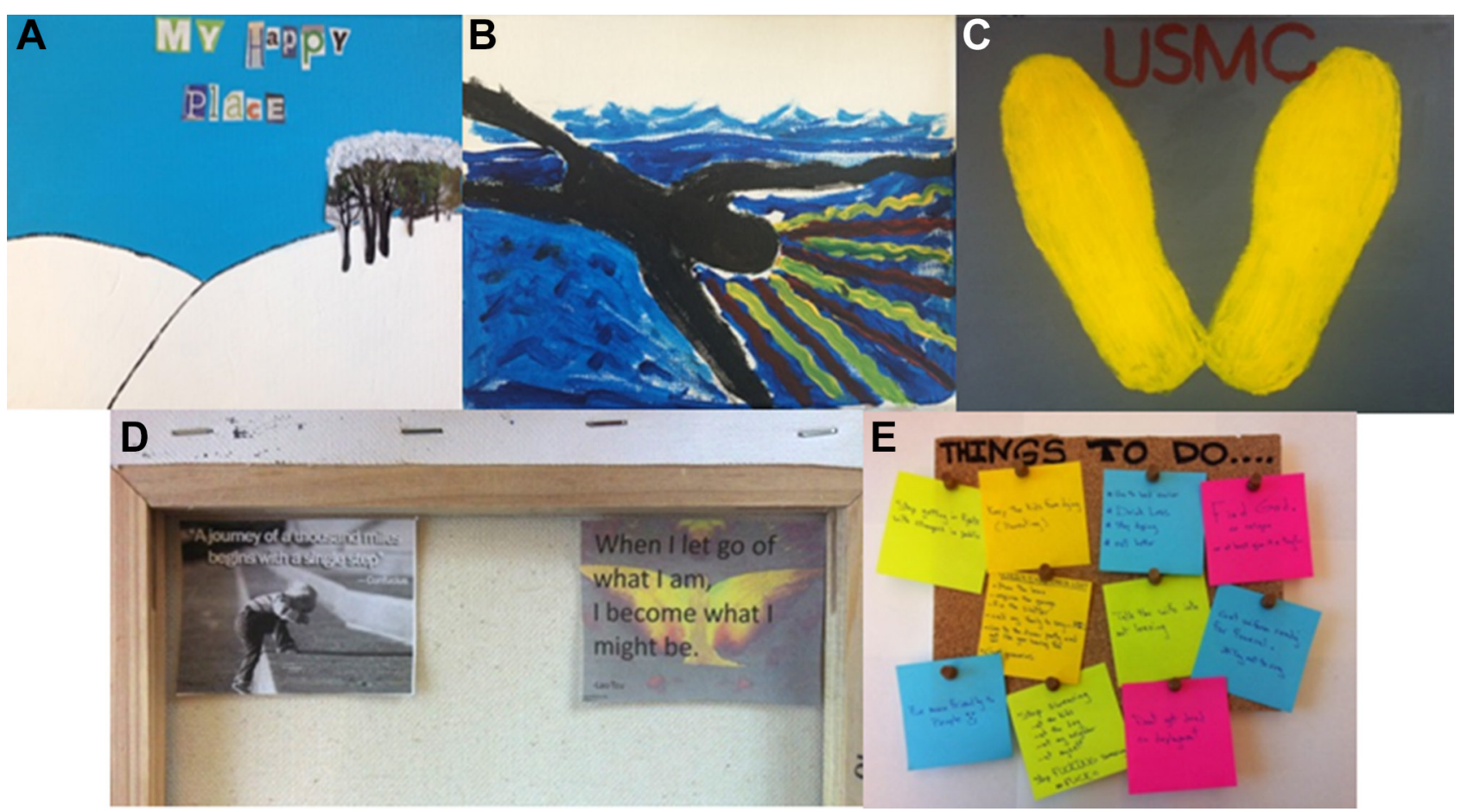

Figure 3 (A) After first painting his background landscape, the service member made an image of a cluster of trees and cut out letters to read 'My happy place'. (B) The service member depicted a person floating in water and used yellow and red paint strokes to illustrate one's thoughts seeping in. (C) The service member suggests the yellow footsteps he stood on when he was a new Marine recruit. He stated that the footprints represent where it all started as well as the next steps he will need to take in his life as he anticipates retirement. (D) He then chose to add positive phrases on the back of his montage painting as motivation for moving forward. (E) The service member used adhesive notes on a cork-covered board to outline his future tasks.

words 'refreshing' and 'relief'. Patriotism, commitment to service and courage are evident in figure 4C. The montage includes two popular mottos in military culture, 'People sleep peacefully in their beds at night knowing that rough men stand ready to do violence on their behalf' and 'May the skulls of my enemies be piled as trophies at my feet'.

\section{DISCUSSION}

We conducted a qualitative analysis of montage paintings $(n=240)$ made by active-duty military service members with traumatic brain injuries and related psychological health conditions. The findings of this study are congruent with results from recent art therapy research that has presented therapeutic elements beneficial for service members: (1) progressive exposure, (2) externalisation for processing, (3) reactivation of pleasure, (4) promotion of self-efficacy and (5) formulation of a reconsolidated narrative. ${ }^{12225-28}$ The montage paintings created by the service members reflected relevant themes described literally through the use of text and/or pictorially through the use of visual metaphors.

Service members at the NICoE have used art therapy in an integrative setting to manage symptoms of TBI and underlying psychological health conditions. Group art therapy was found to be a positive experience for participants in this study. The
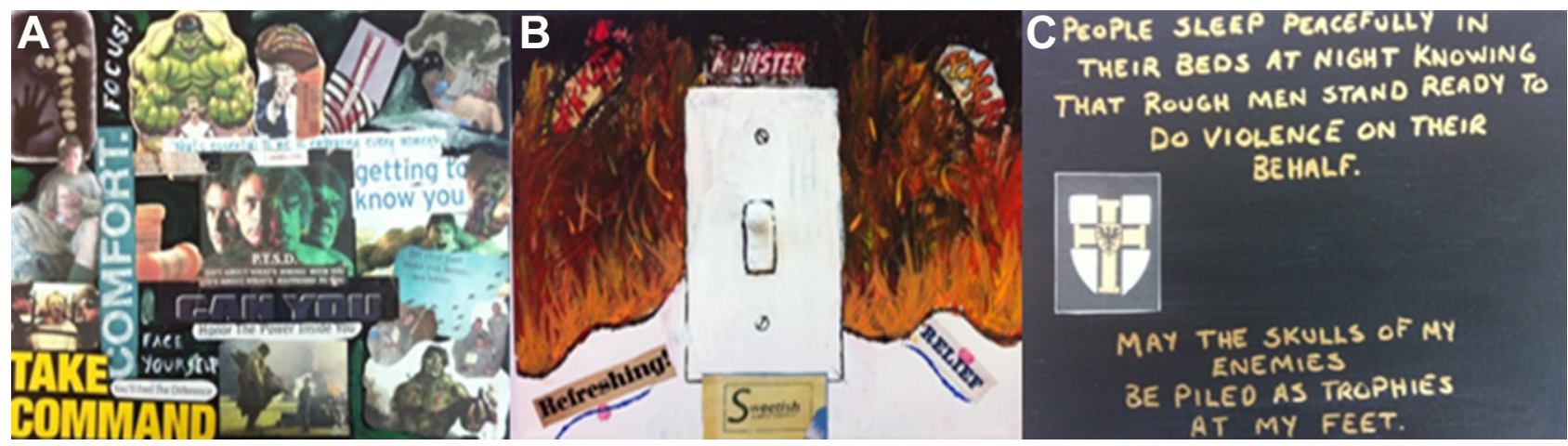

Figure 4 (A) The service member worked with focused intention to reflect his experience with PTSD. He relied on images of the Hulk character to explain how he struggles to contain his anger and come to grips with the 'who' he is inside. (B) The service member mounted an electrical switch to his board to illustrate the 'switch' he feels inside. The upper half was described as the fiery, aggressive side and the lower half with the words 'refreshing' and 'relief' alongside a package of artificial sweetener represent his nice side. (C) This service member used gold to write popular quotes about patriotism and courage beside his military insignia. PTSD, post-traumatic stress disorder. 
data sample indicated that $41.3 \%$ of participants spontaneously and specifically described the art making experience to be enjoyable; $30.4 \%$ were able to share their artwork with clinicians and $35.4 \%$ engaged socially in the group, sharing concerns. Significant changes to identities are experienced as service members shift from active to non-active military service. ${ }^{52}$ In group art therapy, anxieties can be effectively contained in the group, with the therapist and through the created art product. ${ }^{53}$ Simply being present with others who hold similar experiences reduces isolation and forges connection. ${ }^{42}$ The gratification gained by the service members from the art therapy experience resulted in increased pleasure, increased socialisation and greater openness about the recovery processes.

Derailing combat injuries and the accompanying psychological anguish disrupt the strong sense of identity held by service members and strip them of their abilities to actively participate in the experiences that had once held them safe in solidarity. ${ }^{52}$ Group treatment with service members can reveal vulnerability and psychological fragility that are foreign and contradictory to the solidarity and leadership of the collectivist military culture. ${ }^{4052}$

The montage painting, created at the week 4 time point, is sequential to the mask created during week 1 of treatment at the NICoE. The montage painting, an assemblage of preprinted images, text and more traditional art materials, enables progressive exposure and externalisation for processing. The $8 \times 10$ ' canvas provides a sturdy surface on which to integrate the more fragmented aspects of self, treatment and future as a civilian. Because it is a small composition, the service members gain a sense of mastery to select the most pertinent aspects of their recovery process. Service members choose whether to work abstractly or figuratively. Some use personal images and writing. The process promotes self-efficacy.

A central tenet of art therapy theory postulates that all artists, regardless of skill level, project underlying conflicts in art making. ${ }^{54}$ The rich content of the montage paintings reflects the complex recovery experiences of service members. The most frequent codes were the use of nature metaphors $(35 \%)$, reflection of a life story $(28.8 \%)$, memories of deployment $(21.7 \%)$ and references to serenity (17.5\%). Findings also note increases in patriotism $(11.8 \%)$ and hopefulness $(11.1 \%)$. The noted increase in self-awareness can point to the formulation of a reconsolidated trauma narrative as elements of past experiences are integrated into the adaptive coping in the present. ${ }^{1222} 2628$

In art therapy group sessions, wounded service members join together to make meaning from the discrepancies of existing beliefs and current realities. ${ }^{55}$ The shared experience of the group allows service members to be psychologically held in the space while newer identities are being rehearsed. The use of montage painting with the military population enables service members to 'discover the layers of his or her experiences and revisit their story as a therapeutic means of creating, understanding and gaining a sense of mastery'. ${ }^{(17}$, p. 45$)$ The inherent properties of collage and montage painting help to reconcile cognitive and emotional dissonance for trauma-related symptoms.

By externalising underlying feelings in the montage paintings, processing is more easily tolerated. Pleased with their finished products, service members frequently gift their paintings to loved ones with pride. Art therapy aids the larger rehabilitative goals of increasing stabilisation, establishing safety and increasing awareness of symptoms. ${ }^{43}$ The communal experience of group art making fostered increased social connectedness by diminishing feelings of shame and isolation commonly felt by service members managing combat injuries.
Results from this study highlight the complexity of the military culture, necessitating the broader scope of analysis afforded by qualitative research. The dialectic existence of aggressor/ victim, honour/shame and vulnerability/invincibility can be best captured through qualitative research methods. More qualitative research is needed to capture the breadth of military service members in postcombat recovery.

The study has many limitations that warrant attention. The data are secondary and our analysis and interpretation are based on photographs and brief clinical notes. This limits the extent of meaning and attributions we can make for the imagery created by the service members. In addition, the artwork was created in the context of a 4 week intensive outpatient integrative medical care programme facilitated in the safety of group setting by a Masters level art psychotherapist. As such, artmaking that invites exploration of challenging clinical symptoms cannot be replicated in other contexts that do not provide these structures of psychological and physical safety.

There are, however, several areas for further study. Art therapists might collaborate with colleagues in humanities, medical and social sciences to further examine how art therapy helps service members express and communicate their challenges to care providers, peers and family as well as regulate emotion in the short and long term. Further study might also examine if certain types of imagery relate to specific clinical trajectories of recovery as well as if specific types of injuries might be particularly sensitive to creative arts therapies interventions.

\section{CONCLUSION}

The montage paintings serve as visual reflections of the military service members' experiences of TBI and underlying psychological health conditions, and the integrative treatment received at the NICoE medical centre. The paintings helped service members consolidate their experiences into one image and also served as a reminder that treatment for the symptoms is complex and multifaceted. To the best of our knowledge, this is the first article to highlight how paintings created through art therapy support the mental health needs of service members, but further research is needed to better understand how visual self-expression helps with short-term and long-term outcomes. Imagery provides a rich arena for clinicians to engage patients in describing physical and psychological symptoms related to military experiences. Healthcare providers, clinicians and practitioners working with injured service members could benefit from collaborating with art therapists to provide integrative care that honours visual communication for traumatic experiences that cannot be communicated through verbal means alone.

Contributors $\mathrm{MB}$ coordinated all the coding and prepared the literature review. MSW was the lead clinician and facilitated the creation of the montage paintings. GK led the study and reviewed the analysis.

Funding This research was supported through funding from the National Endowment for the Arts, Creative Forces: NEA Military Healing Arts Network.

Disclaimer The identification of specific products or scientific instrumentation is considered an integral part of the scientific endeavour and does not constitute endorsement or implied endorsement on the part of the author, DoD, or any component agency. The views expressed in this (article, speech, presentation and so on) are those of the author and do not reflect the official policy of the Department of Army/Navy/Air Force, Department of Defense or US Government.

Competing interests None declared.

Patient consent Obtained.

Ethics approval Walter Reed National Military Medical Center.

Provenance and peer review Not commissioned; externally peer reviewed. 
Open access This is an open access article distributed in accordance with the Creative Commons Attribution Non Commercial (CC BY-NC 4.0) license, which permits others to distribute, remix, adapt, build upon this work non-commercially, and license their derivative works on different terms, provided the original work is properly cited, appropriate credit is given, any changes made indicated, and the use is non-commercial. See:http://creativecommons.org/licenses/by-nc/4.0/.

\section{ORCID iDs}

Marygrace Berberian http://orcid.org/0000-0001-6642-3426

Melissa S Walker http://orcid.org/0000-0001-9375-567

Girija Kaimal http://orcid.org/0000-0002-7316-0473

\section{REFERENCES}

1 U.S. Government Accountability Office. VA mental health: Number of veterans receiving care, barriers faced, and efforts to increase access (GAO-12-12) [PDF file]. 2011 https://www.gao.gov/products/GAO-12-12 (accessed 17 Feb 2018).

2 Institute of Medicine. Returning home from Iraq and Afghanistan: Assessment of readjustment needs of veterans, service members, and their families. Washington, DC: National Academies Press, 2013.

3 Pew Research Center. The military civilian gap: War and sacrifice in the post-9/11 era. 5. 2011 http://www. pewsocialtrends.org/2011/10/05/war-and-sacrifice-in-the-post911-era/ (accessed 17 Feb 2018).

4 Scholten J, Danford E, Leland A, et al. Templated Interdisciplinary Rehabilitation Care Plan Documentation for Veterans With Traumatic Brain Injury. Prof Case Manag 2016;21:266-76.

5 Department of Veterans Affairs. VHA handbook 1172.01: Polytrauma system of care. Washington, DC: Veterans Health Administration, 2013. https://www.va.gov/ optometry/docs/VHA_Handbook_1172_01_Polytrauma_System_of_Care.pdf. (accessed 17 February 2018).

6 Pape HC, Lefering R, Butcher $\mathrm{N}$, et al. The definition of polytrauma revisited: An international consensus process and proposal of the new 'Berlin definition'. J Trauma Acute Care Surg 2014;77:780-6.

7 Defense and Veterans Brain Injury Center. DoD Worldwide numbers for TBI [PDF file]. 2017 http://dvbic.dcoe.mil/dod-worldwide-numbers-tbi (accessed 17 Feb 2018).

8 Spoont MR, Nelson DB, Murdoch M, et al. Impact of treatment beliefs and social network encouragement on initiation of care by VA service users with PTSD. Psychiatr Serv 2014;65:654-62.

9 Shin LM, McNally RJ, Kosslyn SM, et al. A positron emission tomographic study of symptom provocation in PTSD. Ann N Y Acad Sci 1997;821:521-3.

10 Van der Kolk B. The body keeps the score: Brain, mind, and body in the healing of trauma. New York, NY: Sage, 2014.

11 Ramirez J, Erlyana E, Guilliaum M. A review of art therapy among military service members and veterans with post-traumatic stress disorder. Journal of Military and Veterans' Health 2016;24:40-51.

12 Smith A. A literature review of the therapeutic mechanisms of art therapy for veterans with post-traumatic stress disorder. International Journal of Art Therapy 2016;21:6674.

13 Walker MS, Kaimal G, Koffman R, et al. Art therapy for PTSD and TBI: A senior active duty military service member's therapeutic journey. Arts Psychother 2016:49:10-18.

14 Walker MS, Kaimal G, Gonzaga AML, et al. Active-duty military service members' visual representations of PTSD and TBI in masks. Int I Qual Stud Health Well-being 2017:12:1267317.

15 American Art Therapy Association. About the American Art Therapy Association. 2017 https://arttherapy.org/about/ (accessed 17 Feb 2018).

16 National Endowment for the Arts. Creative arts therapy a useful tool for military patients. National Endowment for the Arts expands military healing arts partnership. 2015 https://www.arts.gov/news/2015/creative-arts-therapy-useful-tool-militarypatients (accessed 17 Feb 2018).

17 Lande RG, Tarpley V, Francis JL, et al. Combat Trauma Art Therapy Scale. Arts Psychother 2010;37:42-5.

18 Golub D. Symbolic expression in post-traumatic stress disorder: Vietnam combat veterans in art therapy. Arts Psychother 1985;12:285-96.

19 Nanda U, Barbato Gaydos HL, Hathorn K, et al. Art and Posttraumatic Stress: A Review of the Empirical Literature on the Therapeutic Implications of Artwork for War Veterans With Posttraumatic Stress Disorder. Environ Behav 2010;42:376-90.

20 Langer R. Combat trauma, memory and the World War II veteran. War, Literature, and the Arts: An International Journal of the Humanities 2011;23:50-8.

21 Brunswick M. On the beat: Military Affairs; Vets: Art therapy for PTSD sufferers. Minneapolis, Minnesota: Star Tribune, 2014:3B. (accessed 30 Nov 2017).

22 Collie K, Backos A, Malchiodi C, et al. Art therapy for combat-related PTSD: Recommendations for research and practice. Art Therapy: Journal of the American Art Therapy Association 2006;23:157-64.

23 Harris DA. The paradox of expressing speechless terror: Ritual liminality in the creative arts therapies' treatment of posttraumatic distress. Arts Psychother 2009;36:94-104.
24 Rademaker AR, Vermetten E, Kleber RJ. Multimodal Exposure-Based Group Treatment for Peacekeepers With PTSD: A Preliminary Evaluation. Military Psychology 2009;21:482-96.

25 Avrahami D. Visual art therapy's unique contribution in the treatment of posttraumatic stress disorders. J Trauma Dissociation 2005;6:5-38.

26 Gantt L, Tinnin LW. Support for a neurobiological view of trauma with implications for art therapy. Arts Psychother 2009;36:148-53.

27 Kopytin A, Lebedev A. Humor, Self-Attitude, Emotions, and Cognitions in Group Art Therapy With War Veterans. Art Therapy 2013;30:20-9.

28 Lobban J. The invisible wound: Veterans' art therapy. International Journal of Art Therapy 2014;19:3-18.

29 van der Kolk B. Beyond the talking cure: Somatic experience, subcortical imprints and the treatment of trauma. In: Shapiro F, ed. EMDR: Promises for a paradigm shift. NY: APPA Press, 2002:57-83.

30 Tripp T. A body-based bilateral art protocol for reprocessing trauma. In: King J, ed. Art therapy, trauma and neuroscience: Theoretical and practical perspectives. NY: Routledge, 2016:173-94.

31 Lusebrink VB, Hinz LD. The Expressive Therapies Continuum as a framework in the treatment of trauma. In: King J, ed. Art therapy, trauma, and neuroscience: theoretical and practical perspectives. NY: Routledge, 2016:42-66.

32 Gantt L, Tinnin LW. Intensive trauma therapy of PTSD and dissociation: An outcome study. Arts Psychother 2007;34:69-80.

33 Shu IW, Onton JA, Prabhakar N, et al. Combat veterans with PTSD after mild TBI exhibit greater ERPs from posterior-medial cortical areas while appraising facial features. J Affect Disord 2014;155:234-40.

34 van der Kolk B. Posttraumatic stress disorder and the nature of trauma. Dialogues Clin Neurosci 2000;2:7-22.

35 Deci E, Ryan R. Intrinsic motivation and self-determination in human behavior. New York: Plenum Press, 1985.

36 Sandmire DA, Gorham SR, Rankin NE, et al. The Influence of Art Making on Anxiety: A Pilot Study. Art Therapy 2012;29:68-73.

37 Raffaelli T, Hartzell E. A Comparison of Adults' Responses to Collage Versus Drawing in an Initial Art-Making Session. Art Therapy 2016;33:21-6.

38 Scotti V, Chilton G. Collage as arts-based research. In: Leavy P, ed. Handbook of artsbased research. 2017. NY: Guilford Press, 2017:355-76.

39 Verlon A. Montage-Painting. Leonardo 1968;1:383-92.

40 Howie P. Group art therapy: The evolution of treatment and the power of witness. In: Howie P, ed. Art therapy with military populations: History, innovation and applications. NY: Routledge, 2017:64-74.

41 Brailey K, Vasterling JJ, Proctor SP, et al. PTSD symptoms, life events, and unit cohesion in U.S. soldiers: baseline findings from the neurocognition deployment health study. J Trauma Stress 2007;20:495-503.

42 Herman J. Trauma and recovery: The aftermath of violence- from domestic abuse to political terror. New York, NY: Basic Books, 1992.

43 Jones J, Walker M, Drass J, et al. Art therapy interventions for active duty military service members with post-traumatic stress disorder and traumatic brain injury. International Journal of Art Therapy 2017;17:1.

44 Walker M. Art therapy approaches within the National Intrepid Center of Excellence at Walter Reed National Military Medical Center. In: Howie P, ed. Art therapy with military populations: History, innovation, and applications. London, UK: Routledge, 2017:111-23.

45 Walker M. Art Therapy Programming at the National Intrepid Center of Excellence (NICoE). In: Art therapy supporting patient care in medical settings: Toolkit. Alexandria, VA: The American Art Therapy Association, 2011. https://www.arttherapy. org/upload/toolkitmedicalsettings/intrepedcenter.pdf.

46 Braun V, Clarke V. Using thematic analysis in psychology. Qual Res Psychol 2006;3:77-101.

47 Strauss A, Corbin J. Basics of qualitative research: Techniques and procedures for developing grounded theory. 2nd ed. Thousand Oaks, CA: Sage, 1998.

48 Dedoose. [Computer software]. $2018 \mathrm{http}: / / \mathrm{www}$.dedoose.com/about/history (accessed 17 Feb 2018).

49 Doorly P. The truth about art: Reclaiming quality. Winchester, UK: Zero Books, 2013.

50 Ellis A, Abrams M, Dengelegi-Abrams L. Personality theories: Critical perspectives. Los Angeles, CA: Sage, 2009.

51 Gorelick K. Perspective: Rapprochement between the arts and psychotherapies: Metaphor the mediator. Arts Psychother 1989;16:149-55.

52 Smith RT, True G. Warring identities: Identity conflict and the mental distress of American veterans of the wars in Iraq and Afghanistan. Society and Mental Health 2014;4:147-61.

53 Waller D. Group interactive art therapy: Its use in training and treatment. Routledge: East Sussex, 2015.

54 Naumburg M. Dynamically oriented art therapy: Its principles and practice. Chicago, IL: Magnolia St. Publishers 1987.

55 Steger MF, Park C. The creation of meaning following trauma: Meaning making the trajectories of distress and recovery. In: McMackin RA, Newman E, Fogler JM, eds. et alTrauma therapy in context: The science and craft of evidence-based practice. Washington DC: American Psychological Association, 2012:171-91. 